\title{
Centrifugation Studies on the Infectivities of Cellular Fractions Derived from Mouse Brain Infected with Scrapie ('Suffolk strain')
}

\author{
By D. L. MOULD, W. SMITH AND A. McL. DAWSON \\ Animal Diseases Research Association, Moredun Institute, Gilmerton, Edinburgh
}

(Received 4 December 1964)

\begin{abstract}
SUMMARY
Cellular components in homogenates of brain tissue from scrapieaffected mice have been separated by centrifugation in sucrose and caesium chloride density gradients with the objective of location of the scrapie agent and concentration of scrapie activity. Improvements in the relative activity of the fractions removed from sucrose gradients were small but recovery was high in the material sedimented through $0.88 \mathrm{~m}$-sucrose. No peak of activity was observed in zones removed from a caesium chloride gradient and activity throughout remained strongly associated with particulate matter. Ultrasonic disruption had little effect on scrapie activity. Concentrated preparations of sufficient potency for characterization of virus particles by electron microscopy were not obtained. From various experimental evidence the scrapie agent, if a virus, appears to be of small size. The strong association of the agent with tissue debris suggests that the presence of a tissue component may be necessary in the experimental transmission of the condition.
\end{abstract}

\section{INTRODUCTION}

Recent experimental work on the condition of scrapie in animals has emphasized the strong association of the active agent with particulate cell fractions in brain homogenates (Mould \& Smith, 1962; Hunter, Millson \& Chandler, 1963; Hunter, Millson \& Meek, 1964; Mould, Smith \& Dawson, 1964). This has been further substantiated by chromatographic studies of tissue homogenates on DEAE-cellulose columns by Hunter \& Millson (1965). It has also been pointed out that there may be species variations in the location and binding of the agent (Mould, Smith \& Dawson, 1964), and that there are both definite histopathological (Zlotnik \& Rennie, 1962, 1963) and possibly biochemical differences (Slater, 1965) in the brain lesions present in diseased mice according as to whether the source of inoculum was derived from a Suffolk sheep or from material passaged in goats.

The experimental procedures reported in this paper were all carried out with the 'Suffolk strain' of mouse scrapie (Zlotnik \& Rennie, 1962, 1963) which produces histopathological lesions not identical with those produced by the 'drowsy goat strain' (Chandler, 1963) investigated by Hunter et al. Centrifugation studies of brain tissue homogenates in sucrose or caesium chloride density gradients have been made with the primary objective of location of the binding sites of the scrapie agent and concentration of scrapie activity. Some of the results have been reported in a brief communication (Mould, Dawson \& Smith, 1964). 


\section{METHODS}

Animal experiments. Moredun Institute stock Swiss white mice were used for all the experiments. The mice were 3-6 weeks old when inoculated. Groups of seven mice were inoculated $(0.03 \mathrm{ml}$.) by the intracerebral route with serial tenfold dilutions of the various tissue preparations and each experiment terminated 5 or 6 months after the inoculation of the mice. Cases of scrapie were examined histopathologically for the presence of scrapie lesions and LD50 values were calculated according to the method described by Mould, Dawson \& Smith, 1965.

Centrifugation of brain tissue homogenates in sucrose. Tissue was provided from the brains of mice in advanced clinical stages of mouse scrapie following the third passage in mice of the Suffolk sheep strain of scrapie. Crude particulate fractions from brain homogenates were prepared by differential centrifugation in $0.32 \mathrm{M}$ sucrose. Brains from three clinically affected mice $(1 \mathrm{~g}$.) were homogenized in $0.32 \mathrm{M}$-sucrose $(10 \mathrm{ml}$.) and centrifuged for $5 \mathrm{~min}$. at $500 \mathrm{~g}$ to remove readily sedimentable tissue debris. The supernatant fluid was successively centrifuged for $10 \mathrm{~min}$. at $1000 \mathrm{~g}, 15 \mathrm{~min}$. at $20,000 \mathrm{~g}$, and $75 \mathrm{~min}$. at $100,000 \mathrm{~g}$ to provide a nuclear, mitochondrial and ribosomal fraction respectively. The sediments were taken up in equivalent volumes of saline $(0.85 \%)$ and serial dilutions in saline prepared from the suspensions and final supernatant fluid for inoculation in mice. The nuclear fraction was not tested.

A further experiment was designed to investigate the possibility of removing scrapie inactive material by a simple centrifugation procedure in sucrose density gradients. Sucrose solutions of increasing concentration were made up in a dilute phosphate-succinate buffer at $\mathrm{pH} \mathrm{7 \cdot 4}$ (Johnson, 1962;0.004 M- $\mathrm{K}_{2} \mathrm{HPO}_{4}, 0.001 \mathrm{M}-$ $\mathrm{KH}_{2} \mathrm{PO}_{4}, 0.004 \mathrm{M}$-sodium succinate). Brains from three clinically affected mice (1 g.) were homogenized in $0 \cdot 1 \mathrm{M}$-sucrose $(9 \mathrm{ml}$.) and centrifuged for $30 \mathrm{~min}$. at $500 \mathrm{~g}$. The supernatant fluid was removed and maintained in a disperse state by gentle agitation throughout the remainder of the procedure. A sample $(0.5 \mathrm{ml}$.) of the supernatant fluid was layered on $1.2 \mathrm{M}$-sucrose $(4.5 \mathrm{ml}$.) in a small centrifuge tube $(5 \mathrm{ml}$.). Three tubes were prepared and centrifuged for $30 \mathrm{~min}$. at 50,000 $\mathrm{g}$ (Spinco Model $\mathrm{L}$, SW 39 rotor; $25,000 \mathrm{rev} . / \mathrm{min}$.) The whole of the supernatant was rejected and the small sediment from each tube pooled and resuspended in saline $(2.5 \mathrm{ml}$.). Another volume $(0.5 \mathrm{ml}$.) of the original supernatant fluid was layered on a density gradient consisting of $1.2 \mathrm{M}$-sucrose $(1.5 \mathrm{ml}$.), $1.0 \mathrm{M}$-sucrose $(1.5 \mathrm{ml}$.), and $0.88 \mathrm{M}$-sucrose ( $1.5 \mathrm{ml}$.). Three tubes were again prepared and centrifuged for $30 \mathrm{~min}$. at $50,000 \mathrm{~g}$. The cloudy zones that formed at the $1 \cdot 2 \mathrm{M} / 1 \cdot 0 \mathrm{M}$ and $1 \cdot 0 \mathrm{M} / 0 \cdot 88 \mathrm{M}$ interfaces were withdrawn through the side of the tube by a syringe and corresponding zones from each tube were pooled. The procedure was repeated in a preformed gradient of $0.88 \mathrm{M}, 0.75 \mathrm{M}$ and $0.60 \mathrm{M}$ - sucrose and finally in a gradient of $0.60 \mathrm{M}, 0.44 \mathrm{M}$ and $\mathbf{0 . 3 0} \mathrm{M}$-sucrose. All the interfacial layers collected were"dialysed against saline and saline dilutions prepared for inoculation into mice. Protein-N in each inoculum was estimated by a micro-Kjeldahl method.

Centrifugation of tissue homogenates in caesium chloride. Brains from four clinically affected mice $(1.56 \mathrm{~g}$.) were homogenized in $0.85 \%$ saline $(15 \mathrm{ml}$.) and centrifuged for $30 \mathrm{~min}$. at $500 \mathrm{~g}$. Equal volumes $(5 \mathrm{ml}$.) of the supernatant fluid were centrifuged for $90 \mathrm{~min}$. at $120,000 \mathrm{~g}$ (SW 39 rotor; $39,000 \mathrm{rev} . / \mathrm{min}$.). One sedimented 
pellet was resuspended in saline for inoculation into mice and the other resuspended in saline $(1 \mathrm{ml}$.) and agitated in an ultrasonic beam $(90,000$ cyc. $/$ sec.; $80 \mathrm{~W}$.) for $20 \mathrm{~min}$. The suspension was diluted $(5 \mathrm{ml}$.) and a portion (1 ml.) layered on $40 \%$ $(\mathrm{w} / \mathrm{v})$ caesium chloride $(4 \mathrm{ml}$.) in a $5 \mathrm{ml}$. centrifuge tube and centrifuged for $20 \mathrm{hr}$ at $100,000 \mathrm{~g}$ (SW39 rotor; $35,000 \mathrm{rev} . / \mathrm{min}$.). No attempt was made to remove visible zones from the tube after centrifugation. Equal volumes ( $1 \mathrm{ml}$.) were taken successively from the top of the gradient. The final sample included the small sediment packed at the base of the tube. The five fractions from the density gradient were dialysed against saline and serial dilutions prepared for inoculation into mice.

Separation in a caesium chloride gradient was repeated with a mitochondrialsized fraction prepared from the brains of two scrapie-affected mice according to the method described by Hunter et al. (1964). The brains ( $0.72 \mathrm{~g}$.) were homogenized in $0 \cdot 25 \mathrm{M}$-sucrose containing $5 \mathrm{~mm}-\mathrm{CaCl}_{2}$. The homogenate $(7 \mathrm{ml}$.) was layered on $0.88 \mathrm{M}$-sucrose $(15 \mathrm{ml}$.), and centrifuged for $60 \mathrm{~min}$. at $50,000 \mathrm{~g}$ (SW 25 rotor; $25,000 \mathrm{rev} . / \mathrm{min}$.). The sediment was resuspended in $0.25 \mathrm{M}$-sucrose $(7 \mathrm{ml}$.$) , a sample$ taken for inoculation into mice, and the remainder $(5.5 \mathrm{ml}$.) layered again on $0.88 \mathrm{M}$-sucrose and centrifugation repeated. The sediment was resuspended in saline (5.5 ml.), a further sample taken for inoculation into mice, and the remainder $(4 \mathrm{ml}$.) agitated in an ultrasonic beam for $\mathbf{3 0} \mathrm{min}$. Equal volumes $(1 \mathrm{ml}$.) were then layered on $40 \%(\mathrm{w} / \mathrm{v})$ caesium chloride $(4 \mathrm{ml}$.) and centrifuged for $24 \mathrm{hr}$ at $100,000 \mathrm{~g}$. Successive layers of fluid of increasing density were withdrawn from the tube contents, dialysed against saline, and serial dilutions prepared for inoculation into mice.

\section{Table 1. Differential centrifugation of scrapie mouse} brain homogenate in $0.32 \mathrm{M}-$ sucrose

Titres are calculated as $-\log _{10}\left(\right.$ LD50) or in terms of protein content as $-\log _{10}$ (specific LD50). The experiment was terminated 5 months after inoculation.

\begin{tabular}{lccc}
\multicolumn{1}{c}{ Inoculum } & $\begin{array}{c}\text { LD50 } \\
\left(-\log _{10}\right)\end{array}$ & $\begin{array}{c}\text { Protein } \\
\left(\mathrm{g} \cdot / \mathrm{ml} \times \times \mathbf{1 0}^{-3}\right)\end{array}$ & $\begin{array}{c}\text { Specific LD50 } \\
\left(-\log _{10}\right)\end{array}$ \\
Initial 10\% homogenate & $\mathbf{5 \cdot 0 3} \pm \mathbf{0 \cdot 2 1}$ & $\mathbf{1 1 \cdot 1 4}$ & $\mathbf{5 \cdot 8 4} \pm 0 \cdot 21$ \\
Mitochondrial fraction & $\mathbf{4 \cdot 7 3} \pm \mathbf{0 \cdot 4 0}$ & $\mathbf{6 \cdot 0 9}$ & $\mathbf{5 \cdot 8 6} \pm 0 \cdot 40$ \\
Microsomal fraction & $\mathbf{4 \cdot 4 6} \pm \mathbf{0 \cdot 3 2}$ & $\mathbf{1 \cdot 8 6}$ & $\mathbf{6 \cdot 1 7} \pm 0 \cdot 32$ \\
Final supernatant fluid & $\mathbf{2 \cdot 0 7} \pm \mathbf{0 \cdot 2 2}$ & $\mathbf{0 \cdot 8 7}$ & $\mathbf{3 \cdot 8 6} \pm 0 \cdot 22$
\end{tabular}

\section{RESULTS}

Centrifugation of brain homogenates in sucrose

Table 1 shows the results of the titration of activity in the crude particulate fractions obtained by differential centrifugation in $0.32 \mathrm{M}$-sucrose. The LD 50 of each inoculum is defined as that dilution of material which induced within the stated experimental period lesions in the brain consistent with those observed in mouse scrapie in half the animals inoculated. The specific LD 50 of each inoculum is defined as the concentration of protein (g./ml.) which induced scrapie in half the animals inoculated. This remained essentially constant in the original homogenate and sediments. There was a significant fall in the scrapie activity of the final supernatant fluid. Complete removal of particulate material is improbable under the density conditions of the sucrose medium.

The distribution of scrapie activity after centrifugation in the pre-formed sucrose 
density gradients is shown in Table 2 and Fig. 1. The data for each sucrose concentration refer to the scrapie activity present in the layer of tissue particles that penetrate a sucrose layer of the stated concentration. Although activity was present throughout all the various layers the highest recovery was in the material sedimenting through sucrose concentrations greater than $0.75 \mathrm{M}$. There was a small increase in the
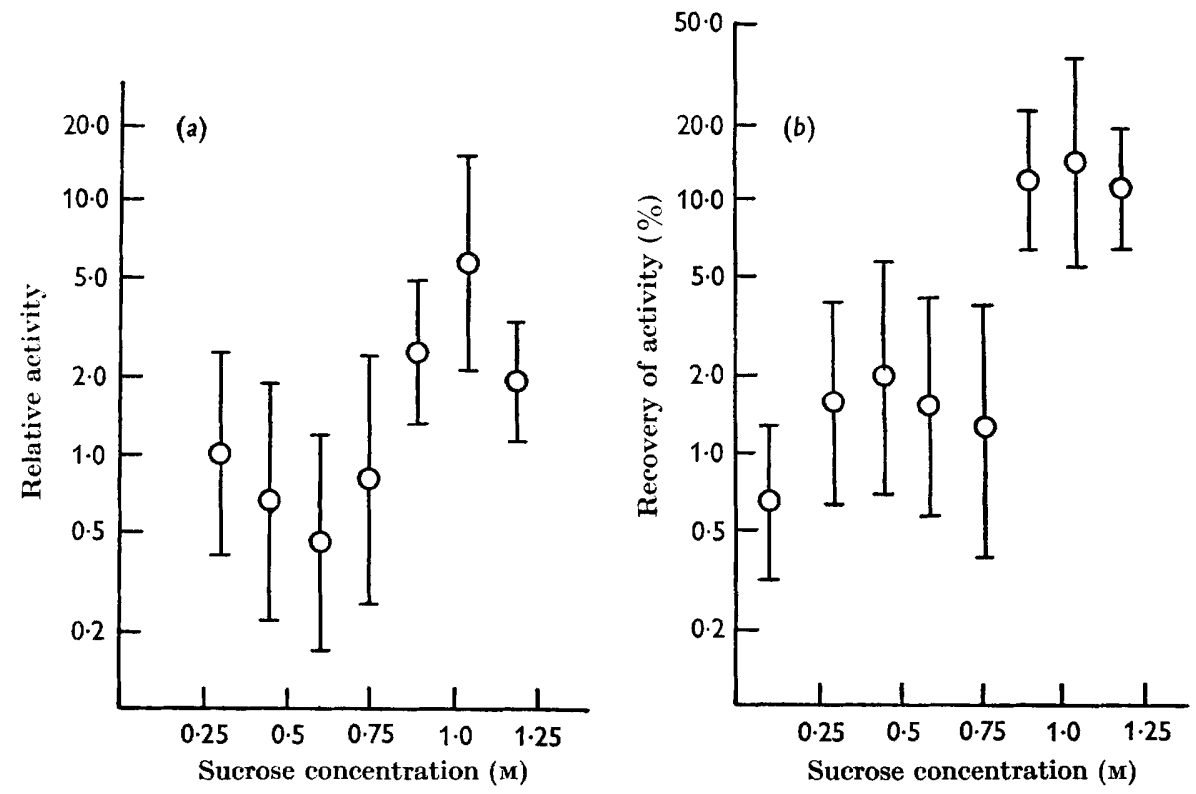

Fig. 1. The recovery of scrapie activity after centrifugation of mouse brain tissue homomogenates in pre-formed sucrose density gradients. $(a)$ Relative activity of zones as function of sucrose concentration penetrated. (b) Recovery of activity in zones as function of sucrose concentration penetrated.

\section{Table 2. Centrifugation of scrapie mouse brain homogenate in layered sucrose density gradients}

The data refer to the scrapie activity in the layer of tissue particles that penetrate a sucrose layer of stated concentration. The LD50 values are corrected to the same effective dilution as the $10 \%$ homogenate. Specific LD50 is expressed as protein concentration (g. $/ \mathrm{ml}$ ). The experiment was terminated 6 months after inoculation.

\begin{tabular}{|c|c|c|c|c|c|c|}
\hline $\begin{array}{l}\text { Sucrose } \\
\text { conc. } \\
\text { (M) }\end{array}$ & $\begin{array}{c}\text { Density } \\
\text { of sucrose } \\
\text { soln. }\end{array}$ & $\begin{array}{l}\text { LD50 } \\
\left(-\log _{10}\right)\end{array}$ & $\begin{array}{c}\text { Recovery } \\
\text { of activity } \\
(\%)^{*}\end{array}$ & $\begin{array}{l}\text { Protein } \\
(\mathrm{g} \cdot / \mathrm{ml} . \\
\left.\times 10^{-4}\right)\end{array}$ & $\begin{array}{c}\text { Specific LD50 } \\
\left(-\log _{10}\right)\end{array}$ & $\begin{array}{l}\text { Relative } \\
\text { activity } \dagger\end{array}$ \\
\hline $0 \cdot 10$ & $1 \cdot 012$ & $2 \cdot 05 \pm 0 \cdot 35$ & $0 \cdot 6$ & $15 \cdot 76$ & $3 \cdot 57 \pm 0.35$ & $0 \cdot 01$ \\
\hline $0 \cdot 30$ & $1 \cdot 037$ & $2.44 \pm 0.52$ & $1 \cdot 6$ & 0.56 & $5.48 \pm 0.52$ & $1 \cdot 0$ \\
\hline $0 \cdot 44$ & $1 \cdot 056$ & $2 \cdot 55 \pm 0 \cdot 60$ & $2 \cdot 0$ & $0 \cdot 99$ & $5 \cdot 32 \pm 0 \cdot 60$ & 0.7 \\
\hline 0.60 & $1 \cdot 075$ & $2.43 \pm 0.55$ & $1 \cdot 6$ & $0 \cdot 96$ & $5.14 \pm 0.55$ & 0.5 \\
\hline 0.75 & 1.094 & $2.34 \pm 0.65$ & $1 \cdot 3$ & $0 \cdot 48$ & $5 \cdot 39 \pm 0.65$ & $0 \cdot 8$ \\
\hline $0 \cdot 88$ & $1 \cdot 113$ & $3.32 \pm 0.27$ & $12 \cdot 0$ & $1 \cdot 21$ & $5.92 \pm 0.27$ & $2 \cdot 7$ \\
\hline $1 \cdot 0$ & $1 \cdot 132$ & $3.40 \pm 0.54$ & $14 \cdot 5$ & 0.67 & $6.26 \pm 0.54$ & $5 \cdot 9$ \\
\hline $1 \cdot 2$ & $1 \cdot 151$ & $3 \cdot 29 \pm 0 \cdot 19$ & $11 \cdot 2$ & $\mathbf{2 \cdot 2 5}$ & $5 \cdot 77 \pm 0 \cdot 19$ & $1 \cdot 9$ \\
\hline \multicolumn{2}{|c|}{$10 \%$ homogenate } & $4 \cdot 24 \pm 0 \cdot 26$ & 100 & $56 \cdot 20$ & $5 \cdot 49 \pm 0 \cdot 26$ & $1 \cdot 0$ \\
\hline
\end{tabular}

* Compared with homogenate as $100 \%$.

$\uparrow$ Specific LD50 of the homogenate divided by that of sample. 
relative activity, calculated from the numerical values for specific LD50, in the more dense layers associated with a corresponding decrease in the less dense material. In Fig. 1 the relative activity and recovery of activity are plotted to a logarithmic scale with estimated deviations as an indication of the inherent error involved in the titration procedures.

\section{Centrifugation of brain homogenates in caesium chloride}

The appearance of the separated zones in the tubes after centrifugation are shown diagrammatically in Fig. 2. The experimental results from the complete sediment (Table 3 ) indicate that only about $0.01 \%$ of the activity was not sedi-

(a)

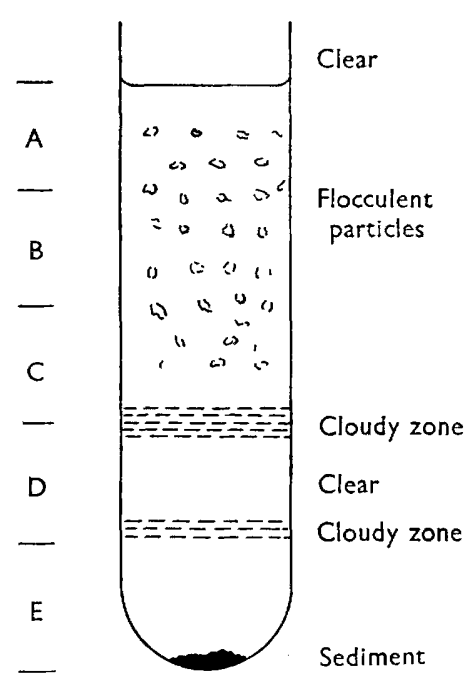

\section{Density}

(g./ml.)

$1 \cdot 10$

$1 \cdot 12$

$1 \cdot 16$

$1 \cdot 22$

$1 \cdot 25$

1.27

$1 \cdot 35$ (b)

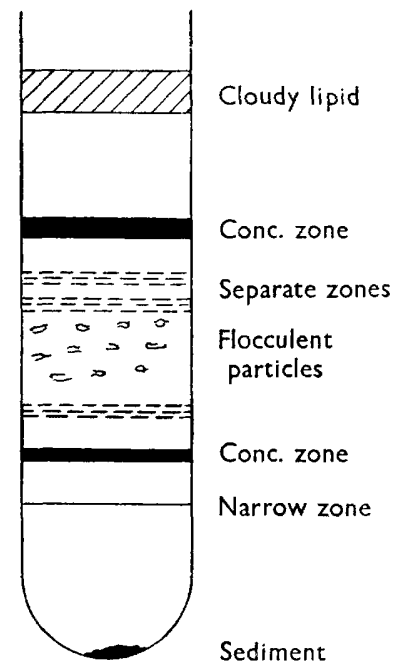

Fig. 2. Ultracentrifugation of scrapie mouse brain tissue homogenates in caesium chloride gradients. Appearance of zones of debris and light scattering zones with volumes of serial fractions (A-E; F-K) collected after centrifugation indicated. $(a)$ Sonicated sediment from brain homogenate layered on caesium chloride. (b) Sonicated mitochondrialsized fraction sedimenting through $0 \cdot 88 \mathrm{M}$-sucrose layered on caesium chloride.

mented under the centrifugation conditions used and that the activity was not affected by ultrasonic treatment of the resuspended sediment. Activity was scattered throughout the gradient but was highest in the low density region of the gradient where particulate matter predominated. The distribution was in general agreement with that already observed in the sucrose gradient. It has been reported (Mould, Dawson \& Smith, 1965) that the poteney of serapie-active material was reduced by $1.8 \mathrm{log}$ units by contact with caesium chloride for $24 \mathrm{hr}$ comparable with the conditions applicable during the centrifugation procedure. A possible diminution to $10^{-3.7}$ of the effective LD 50 titre of the applied zone of active material would therefore be expected after centrifugation in caesium chloride, further decreased to $10^{-3.4}$ by the dilution factor $(1 / 5)$. The spread of activity in the zones collected from the gradient (Table 3 ) agreed with this estimated value and substantiated the previously reported effect of the strong salt solution. 
The experimental titres for the various fractions derived from the portion of mouse brain homogenate sedimenting through $0.88 \mathrm{M}$-sucrose are listed in Table 4 . There was good recovery of activity in the sediment with a high specific LD50. Ultrasonic treatment in this experiment reduced the total scrapie activity. After centrifugation in caesium chloride a number of well-defined zones were observed with a band of flocculated particles (fraction $I$ ) in the gradient over a density

Table 3. Centrifugation of sediment from scrapie mouse brain homogenates in caesium chloride

The experiment was terminated 6 months after inoculation.

\begin{tabular}{|c|c|}
\hline Inoculum & $\begin{array}{c}\text { LD50 } \\
\left(-\log _{10}\right)\end{array}$ \\
\hline $\begin{array}{l}10 \% \text { homogenate } \\
\text { Supernatant fluid above } 100,000 \mathrm{~g} \\
\text { sediment }\end{array}$ & $\begin{array}{l}5 \cdot 67 \pm 0 \cdot 17 \\
1 \cdot 50 \pm 0 \cdot 20\end{array}$ \\
\hline $\begin{array}{l}\text { Material sedimenting at } 100,000 \mathrm{~g} \\
\text { Sediment after ultrasonic treatment }\end{array}$ & $\begin{array}{l}4 \cdot 48 \pm 0 \cdot 56 \\
5 \cdot 47 \pm 0 \cdot 31\end{array}$ \\
\hline $\begin{array}{l}\text { Fractions from caesium chloride } \\
\text { gradient as shown in Fig. } 2 a\end{array}$ & $\begin{cases}\text { A } & 3 \cdot 76 \pm 0 \cdot 30 \\
\text { B } & 3 \cdot 79 \pm 0 \cdot 18 \\
\text { C } & 3 \cdot 35 \pm 0 \cdot 23 \\
\text { D } & 3 \cdot 08 \pm 0 \cdot 26 \\
\text { E } & 2 \cdot 79 \pm 0 \cdot 25\end{cases}$ \\
\hline
\end{tabular}

Table 4. Centrifugation of material from scrapie mouse brain homogenate sedimenting through $0.88 \mathrm{M}$-sucrose

The experiment was terminated 6 months after inoculation.

\begin{tabular}{|c|c|c|c|c|}
\hline Inoculum & & $\begin{array}{r}\text { LD50 } \\
\left(-\log _{10}\right)\end{array}$ & $\begin{array}{l}\text { Protein } \\
(\mathrm{g} . / \mathrm{ml} \\
\left.\times 10^{-3}\right)\end{array}$ & $\begin{array}{c}\text { Specific } \\
\text { LD50 } \\
\left(-\log _{10}\right)\end{array}$ \\
\hline $\begin{array}{l}\text { Material sedimenting } \\
\text { through } 0.88 \mathrm{M} \text {-sucrose }\end{array}$ & & $5 \cdot 49 \pm 0 \cdot 37$ & $5 \cdot 40$ & $6 \cdot 61 \pm 0 \cdot 37$ \\
\hline $\begin{array}{l}\text { Material after repeat } \\
\text { sedimentation through } \\
0 \cdot 88 \mathrm{~m} \text {-sucrose }\end{array}$ & & $6 \cdot 07 \pm 0 \cdot 35$ & $7 \cdot 53$ & $7 \cdot 23 \pm 0 \cdot 35$ \\
\hline $\begin{array}{l}\text { Sediment after } \\
\text { ultrasonic treatment }\end{array}$ & & $4 \cdot 97 \pm 0 \cdot 29$ & - & - \\
\hline & $\mathbf{F}$ & $2.79 \pm 0.55$ & - & - \\
\hline $\begin{array}{l}\text { Fractions from } \\
\text { caesium chloride } \\
\text { gradient as shown } \\
\text { in Fig. } 2 b\end{array}$ & $\begin{array}{l}\text { G } \\
\text { H } \\
\text { I } \\
\text { J } \\
\text { K }\end{array}$ & $\begin{array}{l}3 \cdot 35 \pm 0 \cdot 23 \\
3 \cdot 52 \pm 0 \cdot 35 \\
3 \cdot 92 \pm 0 \cdot 26 \\
2 \cdot 61 \pm 0 \cdot 50 \\
3 \cdot 07 \pm 0 \cdot 24\end{array}$ & $\begin{array}{c}- \\
- \\
-\end{array}$ & $\begin{array}{c}- \\
- \\
-\end{array}$ \\
\hline
\end{tabular}

range $1 \cdot 16-1 \cdot 22$. A cloudy appearance and activity in the low density fraction (F) suggested that ultrasonic disruption of the particles must have taken place as low density material originally present in the brain homogenate had been removed by repeated sedimentation in $\mathbf{0} \cdot 88 \mathrm{M}$-sucrose. Contact with caesium chloride again reduced the overall recovery of scrapie activity which was spread throughout all the fractions removed from the gradient. The highest activity was observed within the density range $1 \cdot 10-1 \cdot 22$. 


\section{DISCUSSION}

Although there are histopathological and biological transmission differences (Zlotnik \& Rennie, 1962, 1963, 1965) between the 'Suffolk strain' and the 'drowsy goat strain' of mouse scrapie the sedimentation behaviour of the activities from mouse brain homogenates appear to be similar (Hunter \& Millson, 1964). Any improvement in the purification or concentration of the scrapie agent as indicated by the relative activity (Table 2 ) of the various zones of activity arising in the sucrose gradients was small, but the recovery of scrapie activity was higher in the material sedimented through $0.88 \mathrm{M}$-sucrose in agreement with the results reported by Hunter et al. (1963, 1964). Activity throughout remained strongly associated with particulate matter. No pronounced peak of activity was observed in the zones successively removed from the caesium chloride gradients. At this preliminary stage of attempted fractionation the protein content of the zones was not determined, but visible particles were scattered throughout tested zones. The effect of ultrasonic treatment can be explained either by the disruption of active particles into smaller fragments retaining activity or the release of an active agent followed by strong readsorption to the smaller particles. Prolonged ultrasonics treatment of the mitochondrial fraction tended to reduce the scrapie activity.

The zones isolated from such gradients have all been examined on the electron microscope for morphological characteristics, but except in the case of identifiable mitochondria (Hunter et al. 1964) were of heterogeneous appearance. This difficulty in the application of zonal gradient centrifugation to the separation of cellular fragments from brain tissue with its relatively complicated cytological differentiation has been recently discussed (Eichberg, Whittaker \& Dawson, 1964). If it be assumed that the scrapie agent is closely associated with a single type of subcellular structure in brain tissue, then following homogenization, ultrasonic disruption and differential centrifugation, it would be certain to appear over a wide range of fractions with varying degrees of activity determined only by the amount of bulk material distributed within those fractions.

Many fractions of known biological activity prepared from sheep, goat and mouse scrapie brain homogenates have been examined by electron microscopy for the possible presence of characteristic virus-like particles. At an earlier stage in the investigation this was done with more varied scrapie preparations than could experimentally be subjected to biological testing in sheep or goats. When quantitative measurements of biological activity and purification were achieved with the mouse it became obvious from the low titres in supposedly purified material that sufficient potency had hardly yet been attained such that unequivocal recognition by electron microscopy might be possible. Within this limitation no virus-like particle has been observed. An extensive application by Drs Mackay \& Vantsis (personal communication) of tissue-culture techniques has failed to demonstrate any cytopathogenic effects associated with the addition of scrapie-infected inoculum.

The biological activity, however, of an unfractionated scrapie-affected mouse brain, determined by titration inoculation of serial dilutions of the brain tissue in groups of mice, is high. At a period of 9 months after inoculation the end-point of the titre of scrapie activity is consistently $10^{-8} \mathrm{~g}$. wet tissue $/ \mathrm{ml}$. $(0.03 \mathrm{ml}$. inoculum). If the causal agent of this level of activity is a virus particle with a particle 
infectivity ratio of $100: 1$, a concentration of $10^{10}$ particles $/ \mathrm{ml}$. might be expected in a $10 \%(\mathrm{w} / \mathrm{v})$ brain homogenate. In thin sections of infected tissue an even higher local concentration of virus associated with lesions might be feasible and the possibility of characterization of a particle 50-100 $\mathrm{m} \mu$ diam. greatly enhanced.

A proposition that the scrapie agent is a very small virus $(<25 \mathrm{~m} \mu)$ as yet uncharacterized is substantiated by its adsorption on or occlusion by small tissue particles and the progressive loss of activity in the supernatant fluid from mouse brain homogenates after repeated centrifugation (Mould, Dawson \& Smith, unpublished). The apparent absence of biological activity in free suspension in the absence of tissue particles, combined with the relative stability of the active agent to chemical and physical action in the presence of tissue particles could indicate almost a state of chemical combination with a tissue component. It is significant that in experimental work consistently high activities or titres have only been reached with brain homogenates under physiological conditions of $\mathrm{pH}$ and salt concentration. A change in $\mathrm{pH}$, addition of salts, solvent action or heat have all decreased the potency of the original scrapie activity (Hunter \& Millson, 1965; Mould et al. 1965). This has been, in fact, one of the difficulties encountered during investigations into the preparation of inocula of increased potency.

Although the transmission of scrapie to animals is most successful when tissue is also transferred, experiments have been reported where this was not the situation. Thus dialysates derived from goat brain homogenates and cerebro-spinal fluid were active in goats (Pattison \& Sansom, 1964); extracts in buffer of sheep brain homogenates were active in sheep (Mould \& Smith, 1962; Mould, Smith \& Dawson, 1964); and scrapie was transmitted to the host animal by cerebrospinal fluid from sheep and goat (Stamp et al. 1959; Pattison \& Millson, 1962).

As an addition to the proposition that scrapie activity may be passaged by small free virus particles occluded in fragmented tissue sediments two further conceptions are suggested for experimental verification. First, that the actual transfer of a tissue component itself in the inoculum is necessary and, secondly, that the nature of this component is of importance in the mechanism of adsorption of the inoculum by the recipient tissue.

We are indebted to Mr J. C. Rennie for the histological examination of mouse brain tissue.

\section{REFERENCES}

Chandler, R. L. (1963). Experimental scrapie in the mouse. Res. Vet. Sci. 4, 276.

Eichberg Jun., J., Whittaker, V. P. \& Dawson, R. M. C. (1964). Distribution of lipids in subcellular particles of guinea-pig brain. Biochem. J. 92, 91.

Hunter, G. D. \& Mrusson, G. C. (1965). Studies on the heat stability and chromatographic behaviour of the scrapie agent. J. gen. Microbiol. 37, 251.

Hunter, G. D., Millson, G. C. \& Chandler, R. L. (1963). Observations on the comparative infectivity of cellular fractions derived from homogenates of mouse-scrapie brain. Res. Vet. Sci. 4, 543.

Hunter, G. D., Mrllson, G. C. \& Meek, G. (1964). The intracellular location of the agent of mouse scrapie. J. gen. Microbiol. 34, 319.

Johnson, M. K. (1962). Treatment of subcellular particles prior to assay of the enzymatic marker, succinic dehydrogenase. Nature, Lond., 196, 1210.

Mould, D. L., Dawson, A. McL. \& Smrth, W. (1964). The infectivities of brain-cell fractions from mice infected with Suffolk sheep scrapie agent. Biochem. J. 91, 13 P. 
Mould, D. L., Dawson, A. McL. \& Sмiтh, W. (1965). Scrapie in mice. The stability of the agent to various suspending media, $\mathrm{pH}$ and solvent extraction. Res. Vet. Sci. 6, 151.

Mould, D. L. \& Sмrth, W. (1962). The causal agent of scrapie. I. 'The extraction of the agent from infected sheep tissue. J. comp. Path. 72, 97.

Mould, D. L., Smith, W. \& Dawson, A. McL. (1964). The elution behaviour of scrapie brain tissue through calcium phosphate columns. J. gen. Microbiol., 35, 491.

Pattison, I. H. \& Millson, G. C. (1962). Distribution of the scrapie agent in the tissues of experimentally inoculated goats. J. comp. Path. 72, 233.

Pattison, I. H. \& Sansom, B. F. (1964). Dialysis of the scrapie agent. Res. Vet. Sci. $5,340$.

Sl.ATER, J. S. (1965). Succinic dehydrogenase, cytochrome oxidase and acid phosphatase activities in the brains of scrapie-infected goats and mice. Res. Vet. Sci. 6, 155.

Stamp, J. T., Brotherston, J. G., Zlotnik, I., Mackay, J. M. K. \& Smith, W. (1959). Further studies on scrapie. J. comp. Path. 69, 268.

Zlotnik, I. \& Rennie, J. C. (1962). The pathology of the brain of mice inoculated with tissues from scrapie sheep. J. comp. Path. 72, 360.

Zlotnik, I. \& Rennie, J. C. (1963). Further observations on the experimental transmission of scrapie from sheep and goats to laboratory mice. J. comp. Path. 73, 150.

Zlotnik, I. \& Rennie, J. C. (1965). The experimental transmission of mouse passaged scrapie to goats, sheep, rats and hamsters. J. comp. Path. (in the press). 